\title{
ANGÚSTIA, VERDADE E "SUBJETIVIDADE": KIERKEGAARD INFLUENCIANDO HEIDEGGER
}

\author{
Lauro Ericksen
}

\author{
Universidade Federal do Rio Grande do Norte
}

\begin{abstract}
Resumo: Aborda as influências admitidas e não admitas por Heidegger em Ser e Tempo acerca do pensamento de Kierkegaard. Analisa as notas de rodapé em que tais influências são textualmente aceitas e indicadas como insuficientes para uma apresentação mais robusta de uma crítica metafísica, debatendo os elementos centrais da angústia e da existência que permeiam o embate lançado. Expõe que a crítica heideggeriana ao entendimento de Kierkegaard se apoia em diferenças terminológicas e conceituais da tradição hegeliana, e não propriamente em equívocos no entendimento kierkegaardiano. Pormenoriza as influências kierkegaardianas textuais e oferece outros elementos não admitidos por Heidegger, tais como a verdade e a subjetividade. Aponta a questão da verdade e da subjetividade como o maior ponto de conexão entre os dois pensadores. Conclui que Heidegger opera uma mera remodelagem, sem trazer elementos originalmente dissonantes em sua apresentação, do pensamento kierkegaardiano.
\end{abstract}

Palavras-chave: Metafísica; existencialismo; angústia; verdade; subjetividade.

\begin{abstract}
The paper discusses the influences of Kierkegaard on Heidegger's Being and Time (both textually accepted and not accepted influences). It analyzes the footnotes where the influences are accepted and promptly rejected as inssuficient to a more solid anti-metaphysical presentation, also apporaching the pivotal themes of anxiety (dread) and human existence. It posits the heideggeriana criticism on Kierkegaards is based on conceptual and terminological differences acquired from hegelian tradition, and they are not propperly kierkegaardiano misunderstandings on these themes. It scrutinizes textual influences of Kierkegaard on Heidegger and other non-admitted issues, such as truth and subjectivity. It points the question of truth and subjectvity as a major connection between the authors. It concludes that Heidegger only remodels Kierkegaard main core of thought, not bringing originally dissonante elements to the presentation of truth and subjectivity.
\end{abstract}

Keywords: Metaphysics; existentialism; anxiety; truth; subjectivity.

\section{Introdução}

$\mathrm{O}$ artigo traça um paralelo comparativo entre pensamento contido na primeira fase de Heidegger (basicamente no contexto de Ser e Tempo) e o pensamento de Kierkegaard. $\mathrm{O}$ processo de análise e de interpretação filosófica busca abordar os pontos de intersecção entre o pensamento de Kierkegaard e de Heidegger para se chegar à conclusão de houve apenas uma remodelagem ou se há uma inovação preponderantemente válida (e em quais aspectos ela se afirma presente na obra do aludido pensador). 
Para o empreendimento proposto no trabalho em tela, há de se pinçar, além das referências explícitas que Heidegger faz a Kierkegaard em Ser e Tempo (expressas em duas notas de rodapé distintas), há de se fazer um breve comparativo entre os dois pensadores mencionados quando se trata da questão da verdade (e da não-verdade). No tema em apreço a verdade é colocada lado a lado com a "subjetividade" do homem e ela é trabalhada de modo conjunto com esse outro elemento fundamental. Para que o estudo em apreço logre êxito, é de grande valia esmiuçar alguns detalhes terminológicos e da época em que cada um dos pensadores escreveu sob pena de se recair em anacronismos ao de desenvolver essa análise conjugada dos dois autores em temas conexos e correlatos, mas que demandam a devida atenção para que não sejam confundidos ou jogados no mesmo arcabouço teórico e conceitual comum.

Dessa forma, o presente artigo, didaticamente, além da presente e sucinta introdução, divide-se em mais três seções, incluindo-se nessa contagem uma seção que se dedica a dar o fechamento ao tema. Na seção subsequente será analisada a primeira nota de rodapé que Heidegger referencia Kierkegaard, explanando a crítica heideggeriana ao caráter "psicológico" e "teológico" dos escritos kierkegaardianos, dando a entender que ele não havia chegado no cerne filosófico da "angústia" (um dos temas que Heidegger admite ter como fonte as obras kierkegaardianas). $\mathrm{Na}$ terceira seção, faz-se uma abordagem da outra nota de rodapé de Ser e Tempo que Kierkegaard é citado, explanando porque ele não atinge o status ontológico pretendido por Heidegger e emendase a análise da nota de rodapé com o estudo da verdade e da subjetividade ofertado pelos dois autores em relevo, aproximando a leitura dos dois sob o entendimento anti-metafísico repartido por ambos. As considerações finais, ao final do texto, almejam dar um fechamento ao tema tratado, indicando que há uma proximidade entre o pensamento de Kierkegaard e de Heidegger maior que esse último vem a de fato admitir, apresentando elementos textuais dos dois para fundamentar tal assertiva.

\section{Heidegger remodelando a angústia kierkegaardiana}

Dentro do enquadramento histórico da tradição filosófica é comum se apontar que Kierkegaard e Heidegger se encontram no mesmo traçado contemporâneo do que se convencionou denominar de "existencialismo". Kierkegaard seria um dos percussores desse movimento existencialista (de viés cristão), e Heidegger, por seu turno, seria um dos grandes expoentes da continuação do existencialismo, agora sob a influência da fenomenologia, fundindo-se o seu pensamento em uma espécie de existencialismofenomenológico (HEIDEGGER, 2008, p.74). Essa ramificação do existencialismo agrega tanto a questão da existência do homem como um tema 
sempre presente na preocupação do pensador, bem como também se ocupa, metodologicamente, da aparição fenomenológica de alguns temas existencialmente relevantes.

Simplesmente por compartilharem o indicativo básico do existencialismo filosófico já se pode asseverar que há uma influência kierkegaardiana no trabalho de Heidegger, todavia, ainda que não seja uma mera suposição interpretativa, tal conexão é bastante simplória e frágil (principalmente quando se afere que Kierkegaard era fervorosamente cristão e Heidegger não possui esse rótulo estampado de forma evidente em suas obras), caso se baseie unicamente em descrições de enquadramento no padrão dos ramos da filosofia contemporânea. Por causa dessa fragilidade argumentativa é necessário traçar paralelos comparativos entre o pensamento de Kierkegaard e de Heidegger com o intento de estreitar a relação de influência traçada entre ambos e assim poder compreender como alguns pontos desenvolvidos por Heidegger já se encontravam pensados, anteriormente e de maneira salutar, por Kierkegaard.

Heidegger aponta textualmente para Kierkegaard apenas em duas notas de rodapé. Na primeira delas, contida no parágrafo 40 de Ser e Tempo, Heidegger (2008, p.257) faz menção à importância do pensamento de Kierkegaard acerca da angústia (Angst), mas o minimiza dizendo que foi feito no contexto "teológico" e com uma exposição "psicológica do tema". $\mathrm{Na}$ segunda menção, contida no parágrafo 45 da mesma obra, Heidegger (2008, p.308) aponta que Kierkegaard falou com propriedade sobre a existência humana (dando a entender algo que qualquer manual de filosofia aponta de forma inarredável: que ele seria um dos ícones percussores do existencialismo), no entanto, ainda que sua abordagem seja de grande relevância histórica e também deveras "edificante" (termo efetivamente utilizado por Heidegger), Kierkegaard não conseguiu penetrar no âmago ontológico da questão, estando preso ainda às amarras conceituais do hegelianismo (mero tratamento ôntico).

Essas menções em notas de rodapé são os elementos textuais explícitos em que há uma conexão entre o pensamento de Heidegger e de Kierkegaard, melhor dizendo, essas notas são os pontos de estreitamento do pensamento dos dois autores que são efetivamente confessados por Heidegger (o que, de maneira alguma, indiquem que sejam apenas essas as influências de Kierkegaard em seu pensamento, implicitamente, como se verá mais adiante, outras influências não confessadas ou admitidas poderão ser levantadas e debatidas). Contudo, pode-se pensar que existem outros elementos kierkegaardiano escondidos (ou não reconhecidos) em seu pensamento, como se assunção de tais elementos fosse um decréscimo a sua originalidade 
filosófica, desmerecendo-o como um dos grandes pensadores contemporâneos do século XX.

Derradeiramente, Heidegger é mais influenciado por Kierkegaard do que ele irá admitir em seus escritos (MCCARTHY, 1978, p.102), e é justamente isso que os apontamentos da presente seção visam explicitar. O trabalho em desenvolvimento não tem por escopo diminuir o prestigio ou a relevância do pensamento heideggeriano ao buscar suas influências em Kierkegaard, muito pelo contrário, é uma forma de fortalecer e desenvolver seu pensamento ao se revelar quais pontos foram resgatados (ou, quiçá, remodelados) por Heidegger em Kierkegaard. Assim, de plano, há de se indicar que não foram apenas os pontos indicados nas notas de rodapé em menção que influenciaram Heidegger, há outros que serão analisados adiante.

Ainda que Heidegger não admita claramente toda a extensão da influência do pensamento kierkegaardiano, uma miríade de comentadores expressivos como Günter Figal (2000, p.150), Jean Wahl (1974, p.221) e Emmanuel Mounier (1962, p.138) indica que a influência de um sobre o outro se espraia por caminhos bem mais extensos que os admitidos textualmente. Ademais, os mencionados pesquisadores elencam como pontos de estreitamente entre o pensamento de Kierkegaard e Heidegger principalmente o tratamento da "subjetividade" e a rejeição da tradição metafísica como um todo, acrescente-se a esses dois tópicos a noção primitiva de autenticidade já contida na obra de Kierkegaard (1991, p. 68), especialmente em O Conceito de Ironia, obra basilar de Kierkegaard em que se constrói a noção pretérita de "autenticidade" como uma subjetividade da subjetividade, a semente daquilo que Heidegger posteriormente chamará de compreensão "pré-ontológica" da realidade.

Antes de indicar os pontos de aproximação não revelados textualmente por Heidegger em Ser e Tempo é necessário tecer alguns breves comentários sobre os pontos que ele efetivamente cita nas notas de rodapé dos parágrafos 40 e 45 (já aludidas no início dessa seção). Na primeira nota citada, Heidegger usa como destaque a obra de Kierkegaard (2011, p. 66), O Conceito de Angústia, para, "superficialmente", embasar seu pensamento. Ele minimiza a influência de Kierkegaard dizendo que o tratamento dado por ele foi "psicológico" e que o contexto de análise era de viés "teológico". Certamente, as constatações "demeritórias" feitas por Heidegger são "válidas" (ao menos pode-se compreender que elas são parcialmente procedentes de um ponto de vista estritamente técnico). Afinal, é impossível negar que a obra referenciada de Kierkegaard tenha sido gestada sob a ótica teológica e com uma apresentação "psicológica", haja vista que Kierkegaard nem mesmo se definia 
como um "filósofo"1 propriamente dito (PATTISON, 2012, p.91), assumindo ele mesmo, alternativamente, contornos poéticos, literários, teológicos e psicológicos, além de "filosóficos", ressalte-se. Todavia, o que há de se criticar na nota feita por Heidegger é que Kierkegaard não se posiciona como um "filósofo profissional", ou seja, ele não se atém academicamente a perseguir o ideal filosófico de maneira detida ou encerrada numa leitura estrita (dos ditames profissionais, como outros pensadores o fazem).

Ou seja, Kierkegaard por meio dos pseudônimos e através de sua expressão poética não se limita aos horizontes filosóficos, ele transita por vários momentos temáticos de sua análise sobre a angústia, tendo vieses teológicos e psicológicos mais evidenciados, mas também tocando em temas de relevância claramente filosófica. Dessa forma, ao tratar Kierkegaard como um "teólogo"2 ou como um "psicólogo" (que seria uma acepção bastante diferente do profissional da psicologia hodierna), Heidegger acaba por desmerecer a influência que Kierkegaard exerce sobre ele, uma vez que não foram as palavras de um filósofo propriamente dito que serviram de saliência. Assim, ele não teria a pujança argumentativa de um Platão ou de um Aristóteles, ou até mesmo de um Kant, para que se ter em conta um exemplo mais próximo temporalmente de Kierkegaard, e de Heidegger. Aliás, esse nem sequer foi o objetivo de Kierkegaard com os seus escritos.

Apartando-se do desmerecimento infundado mencionado anteriormente há de se indicar que, semelhantemente ao que pondera Kierkegaard, Heidegger também aceita a angústia (ou ansiedade - Angst) ${ }^{3}$

\footnotetext{
1 Kierkegaard pode ser considerado um livre pensador, suas obras não se restringem unicamente à Filosofia, embora, de um modo ou de outro, acabem por tangenciar esse tema.

2 Ironicamente, na pós-filosofia contemporânea, não há contornos definidos que indiquem o momento que um pensador deixa de ser filósofo para ser um literato, ou um teólogo, e, por vezes, até mesmo um psicólogo (no sentido filosófico do termo, e não no sentido da psicologia clínica vinculada à área da saúde). Esse entendimento sem contornos definidos é irônico porque deriva de premissas culturalistas heideggerianas, algo que, aparentemente, textualmente, ele parece desprezar em Ser e Tempo.

${ }^{3}$ Saliente-se que em algumas traduções dos textos de Kierkegaard e de Heidegger o termo Angst pode vir tanto traduzido como angústia como por ansiedade. Ainda que não se tenha uma diferenciação propriamente etimológica para se optar por um ou por outro, a escolha feita para que se uso o primeiro consiste no intento de não se ter uma interpretação propriamente psicanalítica desse termo. Caso o termo ansiedade fosse utilizado, ele poderia dar azo à conjecturas de natureza dessa ordem, o que não é minimamente correspondente ao escopo do presente trabalho. Ademais, coloquialmente, nas línguas germânicas, o vocábulo Angst, no sentido de ansiedade, finda por adquirir um sentido de "medo", semelhante ao termo phobos (transliterado do original em grego por: comumente encontrada em termos coloquiais na língua dinamarquesa (língua original em que Kierkegaard escreveu, e até 1924 era traduzida para o inglês como dread (TANNER, 1992, p.30) termo semelhante a "pavor" em português -, sendo posteriormente traduzido por "anxiety", pois a tradução como dread algo que não satisfazia plenamente o seu sentido original na língua original dos escritos. Ainda assim, há autores mais recentes, como, por exemplo, Magda King (2001, p.95), que
} 
como um constitutivo existencial da liberdade do homem, haja vista que ela surge no espaço vertiginoso das possibilidades que confrontam o homem ${ }^{4}$ (na linguagem conceitual da primeira fase do pensamento heideggeriano: Dasein), ademais, esse surgimento possibilita a liberdade segundo um senso de comprometimento, de responsabilidade e de sentido, de acordo com premissas existencialmente atribuídas ao próprio homem (CROCKETT, 2001, p.53). A condução do estudo sobre a angústia por parte de Kierkegaard já dá azo a se vislumbrá-la como o terreno prolífico para que a liberdade do homem possa ser empreendida, assim, a angústia, e, também, o modo como o homem lida com o espectro existencial do que o angustia, é que possibilita que ele exerça a sua liberdade de forma mais "autêntica" o possível.

Heidegger, portanto, arvora-se na mesma perspectiva (que ele chama de "psicológica" por parte de Kierkegaard) para desenvolver o tema em apreço, já que ele não muda a forma como o Dasein (homem) se vê às voltas da angústia. Tanto para Heidegger (2008, p.254), quanto para Kierkegaard (2011, p.110), a angústia é voltada para a interioridade do homem, nada de externo lhe perturba nesse sentido existencialmente peculiar de se experimentar a angústia. Por mais que Heidegger (2008, p.66) tente secularizar Kierkegaard ao dizer que a angústia humana se direciona para a plena vacuidade (e não para Deus, como apontaria prioritariamente Kierkegaard), para o nada, essa tentativa não é um distanciamento do entendimento kierkegaardiano, ela pode ser considerada uma asserção secular do tema, mas jamais um afastamento. Indicar que a angústia ocorre quando o homem se depara com o nada não nega a perspectiva "psicológica" kierkegaardiana, a qual também deposita na interioridade os mecanismos de compreensão do homem, aquilo que se denominou como o "tornar-se subjetivo". Dessa maneira, Heidegger confirma o entendimento kierkegaardiano, re-estatuindo

usam o termo dread para se referir à Angst, mesmo em termos heideggerianos. No entanto, ressalte-se que esse sentido de Angst como sendo o "medo de algo" deve ser totalmente rechaçado nos meandros filosóficos, principalmente quando se está a tratar da filosofia heideggeriana. Todavia, ao se perguntar como faz Jochen Stock em, "Wer hat Angst vor Einsamkeit?" (DORNENREICH, 2001), traduzido livremente por "Quem anseia pela solidão?", tem-se que alguém pode se sentir angustiado por isso, embora ninguém em jogo seja o mais preparado para responder tal indagação (essa, aliás, é a própria conclusão de viés poético proclamada por Stock). Ou seja, ninguém anseia por isso, ou por aquilo, muito menos pelo fenômeno mais originário causado pela própria Angst.

${ }^{4}$ Metodologicamente, há de se fazer a indicação que, por vezes, o termo Dasein no artigo em desenvolvimento é referido como "homem". Esse intercâmbio conceitual não visa dar nenhuma estruturação naturalista ao termo "Dasein", como poderiam atacar os heideggerianos mais ortodoxos. Esse uso "não-conceitual" visa firmar o entendimento, acatado pelo próprio Heidegger, que o projeto do Dasein de Ser e Tempo, não encontrou um fim derradeiro e acabado, de modo que o homem da tradição filosófica não foi totalmente substituído pelo Dasein, tanto que em obras posteriores, Heidegger (2007, p.77) abandona o uso do termo Dasein. 
suas disposições de modo secularizado (PATTISON, 2012, p.291), e não the confere nenhuma roupagem especialmente diferenciada, tampouco se aparta dos elementos teológicos ou psicológicos por ele utilizados. No máximo, Heidegger é capaz de modificar-lhe sutilmente o sentido do tratamento oferecido, afinal, aquilo que o homem (Dasein) encontra ao se angustiar pode ter uma variação terminológica (Deus ou o nada), mas o sentido atribuído ao modo de ser do homem é dado com uma semelhança extraordinária. A diferença entre a angústia se direcionar a Deus ou ao nada é tão arbitrária, do ponto de vista existencial, que não configura nenhuma inovação heideggeriana fazer essa breve modificação no tema em apreço.

O tópico em andamento é bastante debatido e refletido por comentadores de Kierkegaard e de Heidegger, não havendo muito dissenso a respeito da influência daquele sobre este, no entanto, as breves considerações dadas são úteis no sentido de clarificar que Heidegger mesmo quando assume ter sido influenciado, como o faz na nota, acaba por dar uma importância menor que a devida a Kierkegaard, algo que também ocorre na segunda indicada nota do parágrafo 45 a ser pormenorizada adiante.

\section{A diferenciação ontológica heideggeriana: a verdade e a subjetividade em Kierkegaard e Heidegger}

A segunda nota de rodapé em que Heidegger cita Kierkegaard desmerece o tratamento dado por este à questão da existência indicando que a perspectiva ontológica do assunto lhe é "estranha" (desconhecida ou ignorada em um sentido filosófico estrito). Em outras palavras, mais uma vez Heidegger tenta indicar que Kierkegaard não é um filósofo profissional e que não sabe manejar a diferenciação que lhe é pertinente (e original) entre ôntico e ontológico, estando ainda preso às conceituações de matiz hegeliano.

Esse indicativo de Heidegger dá a entender que Kierkegaard ainda era dependente da filosofia hegeliana para tecer seu pensamento (MJÅLAND, 2008, p.100) e que no final das contas nunca conseguiu se desvencilhar delas para ser um pensador original e destacado por si mesmo. Mais uma vez, sob um ponto de vista "estritamente técnico", as ponderações de Heidegger são procedentes, ainda que se possa afirmar apenas parcialmente a dependência de Kierkegaard do aparato hegeliano. Ele era dependente do emprego da dialética para desenvolver seus temas, e tal fato não pode ser negado ou sequer remediado. No entanto, no que diz respeito ao emprego terminológico de conceitos, Kierkegaard só se atém a Hegel através do veículo linguístico de expressão (TOEWS, 1980, p.393), afinal, eles compartilhavam o mesmo aparato conceitual e terminológico por serem próximos na linha temporal da tradição filosófica. O indicativo anterior é semelhante ao ocorrido com Platão 
e Aristóteles, por exemplo, os quais também compartilhavam a mesma estrutura conceitual e terminológica (pelo mesmo motivo indicado). Dessa forma, Kierkegaard acabava não se vinculando à tradição hegeliana como se assumisse o conteúdo de tais termos ferrenhamente, aliás, esse é um dos seus objetos de crítica ao hegelianismo.

Seria impossível que Kierkegaard, em seu tempo histórico, fosse capaz de manejar o "linguajar conceitual" de Heidegger, especificamente a diferenciação entre ôntico e ontológico. Kierkegaard se finca ao sistema metafísico hegeliano para criticar a sua disposição conceitual e sob pena de um anacronismo patente não se pode empregar a terminologia de Kierkegaard às disposições filosóficas de Heidegger. O mais correto a se dizer não é que Kierkegaard não atinge o nível ontológico de análise filosófica (pois esse sucesso lhe era inatingível e, por causa disso, não pode ser dele cobrado), e sim dizer que Heidegger trata do tema da existência de modo mais "sistemático e profissional que Kierkegaard" (CAPUTO, 1987, p.83). Nesse sentido, a crítica heideggeriana é procedente, Kierkegaard não atinge o nível ontológico de análise porque na distinção entre ôntico e ontológico isso ainda não lhe era acessível, todavia, tal fato de maneira alguma macula ou deixa menos relevante as ponderações kierkegaardianas, ao contrário, ele apenas denota as diferenças de época existente entre os dois pensadores.

Há quem aponte que Kierkegaard não alcance o nível ontológico pretendido por Heidegger em virtude de Deus ser para ele uma questão existencial, e não uma questão ontológica, daí ele não ser capaz de chegar nesse nível em separado por unir Deus e o homem no mesmo plano de análise (ELROD, 1975, p.70). Todavia, partindo do pressuposto que Kierkegaard e Heidegger possuem cada uma seu modo uma disposição terminológica diversa, não seria de modo algum possível se querer uma equivalência entre a existência (de fundamento cristão) para Kierkegaard e o mesmo termo para Heidegger, o qual tenta se afastar da definição cristã dada por Kierkegaard, ainda que esse afastamento não seja operado de maneira definitivamente clara e direta no texto. Assim, em termos de equivalência, e não de correspondência estrita, as considerações kierkegaardianas sobre a existência atingem o nível mais claro possível para ele, o nível da subjetividade humana. Nesse nível é que a verdade se encontra disposta, daí não sendo possível derivar nada que seja mais evidente ou mais sublime, algo que Heidegger pudesse atestar com o seu selo ontológico de profundidade ou de esmero filosófico.

Kierkegaard possui uma preocupação bastante evidente em rejeitar as conclusões do sistema hegeliano, embora aceite a posição metodológica por ele utilizada, a dialética. Por causa dessas peculiaridades, é correto afirmar que o pensamento de Kierkegaard ainda está atrelado ao contexto hegeliano. No 31 
entanto, a crítica feita por Heidegger, que Kierkegaard não conseguiu superar as conceituações de Hegel, e por isso não teria logrado êxito em apresentar a existência segundo parâmetros ontológicos, parece ser um tanto quanto deslocada do contexto histórico em que ela se efetiva e também denota uma tentativa de favorecer o próprio pensamento sem dar o devido crédito ao substrato anti-metafísico por ele coletado em Kierkegaard.

Já foi dito nesse trabalho que há uma grande diferenciação terminológica entre o pensamento de Kierkegaard e o de Heidegger, principalmente em função do lapso temporal existente entre os dois autores. Nesse sentido, apegando-se a esse fato, a diferenciação entre eles é algo que tende a se perpetuar e crescer. Todavia, paralelos podem ser delineados em que tal diferença seja sutil e quase imperceptível, dentro de um formato interpretativo mais amplo, que agregue os pontos em comum entre ambos. Trilhando esse entendimento, há de se colocar a questão da verdade, já que, para os dois, o tratamento dado ao tema pode ser aproximado, revelando mais um tema em comum não expressamente admitido por Heidegger em suas citações diretas a Kierkegaard.

Para que a questão da verdade seja mais bem analisada é imperioso deixar assentado desde logo que o adágio kierkegaardiano da "verdade como subjetividade", tão repetido no presente trabalho, é assimilado por Heidegger em Ser e Tempo. Todavia, esse adágio não é repetido com as mesmas palavras, embora o sentido empregado por Heidegger (2008, p.292) seja bastante semelhante ao enunciar que "o Dasein é e está na verdade". Essa passagem, ainda que não se valha diretamente do termo "subjetividade", encontra-se imersa no contexto da "subjetividade" pelo entendimento de que o Dasein "é" e "está" na verdade por meio de sua compreensão (pré) ontológica da realidade.

Heidegger não emprega os conceitos "sujeito" e "objeto" tal como Kierkegaard o faz, a opção por não se utilizar a dicotomia cartesiana de sujeitoobjeto faz parte do seu programa anti-metafísico, boa parte da carga crítica de suas obras se encontra nessa rejeição (e crítica incisiva) terminológica. Assim sendo, Heidegger (2008, p.290) não se vale da noção de "subjetividade" ou "objetividade" para desenvolver a sua noção de verdade, ele pretende se afastar da verdade como correspondência para que o ente possa ser "desvelado" 5 e a verdade, por conseguinte, "encontrada". A verdade acontece subjetivamente para Kierkegaard (2010, p.131), mediada pelo contato com Deus, e em Heidegger ela é o desvelamento do ente que se encontra dado ao Dasein, por

${ }^{5}$ Em referência ao termo grego alétheia (transliterado de á $\lambda \hat{\theta} \theta \varepsilon ı$ ), noção originária que Heidegger busca resgatar em Ser e Tempo. 
isso ele é e está na verdade (CARLISLE, 2005, p.142). Ainda que se possa dizer que a apresentação da verdade de Heidegger se dê em estruturas mais tangíveis ${ }^{6}$, no entendimento de ambos os autores a (busca da) verdade é um questionamento central na dádiva da existência humana. Esse afunilamento da verdade no transcurso da existência é um ponto que aproxima ainda mais o pensamento dos dois autores, a subjetividade humana em Kierkegaard é transmutada na linguagem heideggeriana em um modo de ser próprio do Dasein, aquele modo de "ser-verdadeiro", afinal, como ele mesmo faz questão de indicar, o Dasein "é" e "está" na verdade, ou seja, essa verdade é a sua "própria verdade", ela não está dada ou colocada externamente ao Dasein, como se lhe fosse um "corpo estranho" nesse distanciamento entre ele e o ente desvelado.

Heidegger pode até negar que essa verdade seja a "verdade do sujeito", pois não quer se comprometer com a conceituação sistemática da tradição metafísica que reparte a verdade como correspondência entre o objeto e o sujeito, no entanto, o modo como a verdade é apresentada indica que ela não é capturada essencialmente no mundo, por mais que existam modos de o Dasein ser-no-mundo. Assim, Heidegger centra seus esforços em caracterizar a verdade como algo ínsito ao Dasein (ao homem) e não como algo jogado no mundo dos fatos "objetivamente dados". O Dasein vive e convive com os outros no mundo, mas a sua verdade não lhe é algo externo, faz parte do seu ser, ser-verdadeiro.

Em outras palavras, o que Heidegger está propondo é uma articulação filosoficamente relevante que rejeite a noção de verdade como a capacidade de o sujeito em objetificar o mundo da ciência moderna (BOWIE, 2003, p.9). O Dasein não precisa (ou não possui) do aparato técnico de apreensão contingencial da verdade através de objetos externamente dados ou a ele apresentados, como se ele fosse capaz de capturar a essência daquilo que lhe é externo. Segundo essa explicação, a verdade para Heidegger se estreita no conceito kierkegaardiano de verdade como subjetividade, haja vista que os elementos da interioridade para a compreensão da verdade são dados ao Dasein "pré-ontologicamente", ou seja, antes do intercurso da percepção de algo, "objetivamente" falando.

$\mathrm{Na}$ concepção de Heidegger, portanto, a verdade não é uma propriedade do ser, contrariamente, o ser é que se encontra estruturado

${ }^{6}$ Tal feito ocorrerá especialmente quando ele dela tratará em relação com a obra de arte, na terceira fase do seu pensamento, a qual, saliente-se, não será objeto de estudo da presente tese. No entanto essa indicação, no trabalho em andamento está sendo dada apenas a título ilustrativo, não sendo necessária e imperiosa o seu desdobramento. 
conjuntamente com a verdade (CAPUTO, 1987, p.202), daí a noção básica que o Dasein "é" e, além disso, também "está sendo" (com) a verdade. Heidegger não indica especificamente como se dá essa mediação da verdade por meio do ser, ao contrário de Kierkegaard que deposita suas esperanças na mediação subjetivamente posta do homem para com Deus. Depreende-se, interpretativamente, que em Heidegger essa mediação também seja concebida "subjetivamente", pois o ser está contenção com a verdade, e o Dasein (homem) exerce seus mais variados modos de ser segundo esse ditame.

Deve-se salientar de pronto que a verdade tal como compreendida por Heidegger não representa nenhuma espécie de estado especial do homem ou qualquer sorte de evento extraordinário que lhe garante uma vida autenticamente diferenciada (uma boa vida, ou uma vida justa, para se utilizar sentenças equivalentes). Pelo contrário, a verdade é o que há de mais comum e corriqueiro na cotidianidade do homem, daí ser necessário Heidegger (2008, p.293) indicar que o Dasein é e está tanto na verdade quanto na "nãoverdade". Por causa dessa constituição existencial de "estar na verdade" (e ser na verdade, igualmente), o homem decai na cotidianidade por estar concomitantemente na verdade e na não-verdade. Ao caracterizar a vivência cotidiana do homem como verdade e não-verdade, como uma forma de decadência na inautenticidade (o dia a dia em que nem todas as questões existencialmente relevantes se colocam como prioritárias para as decisões mais simples e mais imediatas) aproxima ainda mais o pensamento de Kierkegaard com o de Heidegger.

Essa aproximação se torna ainda mais clara quando se pensa que a subjetividade, tal como pensada por Kierkegaard (2010, p.219), abriga, também de modo conjunto, a verdade e a inverdade, sendo esta última caracterizada como a vida do homem no pecado cotidiano. Para Kierkegaard (2010, p.220), o homem pode até não querer pecar, ou não pecar intencionalmente em todas as incontáveis vezes que peca, mas o ato de pecar nunca lhe é estranho, seja pela repetição ou pela sua própria origem humana (em remissão ao pecado original).

No entanto, há de destacar que mais uma vez Heidegger (2008, p.230) rejeita a aproximação direta com Kierkegaard através da via teológica, haja vista que ele é assertivo em dizer que a decadência (no original, Verfallensein), compreendida como a colocação do Dasein na não-verdade, não possui um caráter assumidamente "moral" ou "religioso" (no sentido de pecado como tratado por Kierkegaard). Tal como se houvesse uma plena indiferença entre a verdade a não-verdade e como se a não-verdade (heideggeriana) pudesse ser de alguma forma diferenciada da inverdade (kierkegaardiana). Nessa toada, a decadência proposta por Heidegger não seria 
uma decadência axiológica ou valorativa por excelência (como se fosse uma espécie de decadência da humanidade em geral, sua derrocada moral), ela significaria a perda da preocupação existencial do homem consigo mesmo ao se perder em sua lida cotidiana (inautêntica), mas isso não representaria uma ofensa direta a Deus, do modo que ela representaria para a inverdade segundo o entendimento de Kierkegaard.

No posicionamento de Heidegger (2008, p.231), não se diferencia moralmente o homem por estar na verdade ou na não-verdade, ambos os modos de ser contém a mesma expressão moral (ou melhor, conferem nenhum julgamento específico de determinação moralmente válida apta a capacitar ou a inviabilizar a vida do homem). Nenhuma derrocada pecaminosa é afetada pela construção de verdade (e não verdade) inserida na decadência e na inautenticidade do Dasein. A única espécie de avaliação conferida ao Dasein a partir da decadência e da inautenticidade é afeita a sua preocupação consigo mesmo em termos existenciais, em síntese, a sua compreensão de ser-paramorte, permeada pelo momento em que o homem encontra o nada na angústia (HADOT, 2004, p.329). É possível, e bastante provável, que o Dasein não se compreenda por completo e originariamente na decadência e na inautenticidade, todavia, para Heidegger, esses indicativos não são depreendidos teologicamente, de modo que nenhuma pena ou sanção divina são aplicadas a partir de tal inserção existencial.

Ainda que a inocorrência do elemento teológico em Heidegger ao escrutinar a verdade e a não-verdade pareça ser o divisor de águas entre o seu pensamento e o de Kierkegaard, há de se indicar que tal configuração filosófica não os distancia de modo fundamentalmente díspar. Ao retirar o elemento teológico, Heidegger assume, mais uma vez, uma perspectiva ontológica da verdade. Ele a coloca como sendo indiferente ao julgamento moral porventura existente, mas mantém as mesmas estruturas de possibilidade de compreensão existencialmente válidas, tanto que repete a verdade e a não-verdade (inverdade) como elementos básicos da questão em tela, tal como Kierkegaard (2010, p.233) já havia refletido sobre o tema, sob uma perspectiva cristã.

Para Heidegger (2008, p.240), Deus não é o mediador do entendimento subjetivo da verdade, tal como em Kierkegaard, mas ele não prescinde de um aprofundamento semelhante ao "tornar-se subjetivo". A estrutura fundamental da compreensão da verdade do Dasein já é dada por si mesmo, o "Da" do Dasein 7 carrega o modo primordial de descerramento

\footnotetext{
7 Na tradução clássica em português o termo Dasein é convertido em Ser-aí, então o aí carrega a estrutura fundamental de apresentação da verdade em que o Dasein encontra o desvelamento do ente. Todavia, na versão em português utilizada nesse trabalho o Dasein é traduzido como "Presença", de 35
} 
(desvelamento) do ente (MALPAS, 2006, p.186). Por causa do desvelamento do ente segundo a verdade, ela não é estranha ao homem, nem nunca poderia ser, em Kierkegaard (2010, p.141) ela é encontrada subjetivamente, através da mediação de Deus, e em Heidegger, de modo bastante semelhante, ela se encontra dada na estrutura temporal mais elementar ao Dasein, que é o seu próprio "ấ" ("Ser-ấ", ou o "Da"). Por causa dessa caracterização próxima ao homem (Dasein), a verdade é algo que não escapa, não é estranha, e não se distancia daquilo que o homem é, ou daquilo que o homem de modo geral exibe como modo de ser (ou também dizendo, aquilo que ele está sendo). Tanto em Kierkegaard quanto em Heidegger o aprofundamento subjetivo ou a compreensão do modo mais originário de ser-si-mesmo são os constitutivos existenciais básicos da verdade.

Heidegger se distancia da noção "objetiva" de um Deus revelado e que traz consigo a verdade no "mundo". Essa é a maior razão para que ele negue o papel teológico da verdade como subjetividade em Kierkegaard, pois, assumindo a perspectiva transteística ${ }^{8}$, que as estruturas elementares da verdade são mantidas, mas não há revelação exterior de Deus faz com que a sua crítica à metafísica seja ainda mais contundente. Da mesma maneira que o homem não apreende nenhuma essência objetivamente válida a constituir o ser das coisas (pois, o modo de ser do Dasein é constituído e construído através de sua própria existência), Heidegger não deposita em nenhum Deus transcendente a necessidade de se empreender o conhecimento da realidade em última instância (aquilo que é compreendido como o realmente real).

A partir da análise ofertada se compreende outra faceta do pensamento heideggeriano que, mais uma vez, vem a convergir com o

maneira que o "Da" representa o "Pre", dando um destaque à temporalidade ínsita a essa tradução. Em inglês a tradução de Dasein é "Being-there", de modo que o "there" é a estrutura existencial responsável pelo desvelamento em tela. Tanto anteriormente, quanto no desenrolar desse trabalho será usado o termo no original, Dasein, apenas fez-se uma breve menção à tradução em português por Ser-aí para denotar a locução adverbial onde (e quando) a verdade é encontrada pelo ente privilegiado com a compreensão pré-ontológica.

${ }^{8}$ Por transteística (TILLICH, 2014, p.15) se deve compreender que essa abordagem teológica não está nem vinculada ao ateísmo associado ao panteísmo de Spinoza (2001, p.58) - posteriormente mais desenvolvido por Hegel (1977, p.130), nem propriamente a uma definição metafísica do cristianismo medieval (escolástico). 0 transteísmo, portanto, procura transcender o teísmo tradicional, não sendo nem ateu, nem teísta no sentido apresentado. $O$ elemento divino é irrelevante na descrição literal do transteísmo, mas ele pode ser alcançado por cada um, quando há a dedicação a se aperfeiçoar cada vez mais em sua existência (e em sua ligação com o divino). Com base no transteísmo, é possível haver uma apreciação das possibilidades existenciais do homem ao mesmo tempo em que é plausivel (ou implausivel, dependendo da perspectiva teológica que se adote) expressar uma forma de religiosidade convencional (seja ela o cristianismo ou o judaísmo, a título de exemplo). 
pensamento kierkegaardiano: Heidegger assume uma concepção culturalista9 ao definir o ser como um elemento constitutivo da verdade. Ao explicar melhor como essa posição culturalista é assumida por Heidegger há de se dizer que o Dasein não é um constitutivo biológico, nem estrutural nem essencialmente falando. Assim, não existe nenhum componente natural que limite o Dasein a ser aquilo que ele pode ser (e não aquilo que ele é). As possibilidades existenciais do Dasein são dadas em seu constitutivo básico temporal (o seu "Da"), aquilo que o deposita automaticamente na sua verdade e na sua não-verdade. Desse modo, nenhuma compreensão cultural do homem é estranha aquilo que ele pode criar, seu poder de criação encontra-se apenas limitado temporalmente (afinal, depois da morte ele não pode mais se definir, e, logicamente, não pode mais criar nada em sua própria existência), e não subjugado a elementos materiais ou biológicos de definição perene ou universal. A cultura é a expressão máxima de sua própria expressão, é o seu campo de conhecimento por excelência, é o predicativo de sua existência e de sua compreensão de si mesmo e direcionado para si mesmo.

Semelhantemente em Kierkegaard (1955, p.49), ao se rejeitar qualquer sorte de interpretação hesicasta ${ }^{10}$, tem-se um resultado muito semelhante ao pretendido por Kierkegaard. Toda a preparação subjetiva da verdade, e também a relação consigo mesmo mediada por Deus, visam preparar o homem a sociabilidade cultural de seu tempo. Não é através do isolamento e da assunção de uma errante tal qual um eremita que o homem encontra a verdade em sua subjetividade. O "tornar-se subjetivo socraticamente" definido por Climacus tem o intento de colocar o homem numa vivência culturalmente

\footnotetext{
9 Por "visão culturalista" ou "culturalismo", desde os argumentos kierkegaardianos postos em oposição à filosofia hegeliana, deve-se entender a posição superior da cultura (aquilo que é criado pelo homem) em detrimento daquilo que the é dado como natural. Dessa maneira, o culturalismo, utilizado na extensão do texto em desenvolvimento como equivalente do "subjetivismo cultural", encontra-se em franca oposição ao naturalismo (por vezes denominado também como biologismo), ou seja, o elemento de base biológica que forma o homem e o circunda.

10 Tal doutrina mística prevê a observação interna por meio de orações, para que o sacerdote limpe seus pensamentos e se aprofunde subjetivamente, ao mesmo tempo em que assume uma posição eremita (afastamento permanente) perante o mundo. 0 objetivo primordial do hesicasmo consiste em obter uma união com Deus em um nível de aprofundamento que prescinda as imagens, os conceitos e as imagens, por meio da repetição de preces e de orações (WARE, 1995, p.4). Nesse modelo de vida hesicasta não há como manter uma vida socialmente atrelada ao "mundo", é necessária uma "vida solitária" para que se atinjam os objetivos dados. No modelo kierkegaardiano (do subjetivismo cultural) a escada de Clímaco é utilizada pelo seu pseudônimo (ironicamente denominado igualmente de Climacus), a diferença é que ele não assume uma posição atrelada ao hesicasmo, daí a sua necessidade posterior de abandonar a escada e ter uma vivência culturalmente relevante em sociedade. Assim, Kierkegaard se vale da escada de Clímaco apenas metodologicamente e até certo momento do desenvolvimento do seu pensamento e depois a abandona, ele assim procede porque se continuasse com a escada hesicasta teria que se vincular permanentemente à doutrina mística do isolacionismo hesicasta.
} 37 
rica (KIERKEGAARD, 2010, p.176), meio através do qual o conhecimento ético-religioso kierkegaardiano tende a florescer.

Se o paralelo entre Kierkegaard e Heidegger se afigura imperativo também através da verdade, tal como defendido na seção em andamento, há de se depreender que Heidegger também assume uma perspectiva platônica quando se fala de interpretação cultural da verdade. Esse ponto é reciprocamente confirmado a partir do encadeamento conjunto da verdade e da não-verdade tal como apresentado por Kierkegaard (2010, p.225). Até mesmo a consideração de verdade e de inverdade de Kierkegaard não era tão clara em apresentar os elementos de plausibilidade e conveniência para a verdade tal como operado por Heidegger nessa seara.

Se não há uma verdade intrincadamente dada em critérios naturais ou biológicos (WRATHALL, 2010, p.230), o que se escapa do desenvolvimento cultural são apenas narrativas plausíveis para explicar as mais diversas manifestações humanas. Assim, a disposição cultural do Dasein não é uma descrição fechada de seu enquadramento "humano", muito pelo contrário, as possibilidades existenciais mais amplas qualificam o Dasein para ser tudo aquilo que ele vislumbre (poder ser) em um ambiente cultural amplo. Nenhuma definição biológica é limitante para o enquadramento dessas vivências, do mesmo modo que o entendimento sobre si mesmo é o horizonte de todas as possibilidades existenciais para o Dasein.

A verdade (e concomitantemente também a não-verdade) não é um termo absoluto na compreensão dos modos de ser do Dasein. A inconstância e a variabilidade dos modos de ser são acompanhadas da definição (transitória) do que está sendo concebido como "verdade", afinal, as possibilidades de ser, na medida em que são implementadas, é que são capazes de indicar qual a verdade (ou não-verdade) inserta em tais proposições, observadas sob o ponto de vista existencial heideggeriano. A verdade, nessa perspectiva, não é algo que se alça acima do homem, não o transcende e não pode ser manipulada para obliterar as suas possibilidades existenciais. Ela só se afigura como um elemento de apreciação na constância de uma definição daquilo que ela "é" ou "está sendo" orientado para o horizonte temporal em que o homem se interpreta (o futuro, onde são escrutinadas as possibilidades). Sem esse elemento ontológico a verdade não existe como uma efetivação de possibilidade existencial do Dasein, ou seja, se ele é ou está de algum modo existencialmente válido, ali mesmo a verdade é encontrada.

De modo concludente, pode-se apontar mais um encontro aproximativo no pensamento de Kierkegaard e Heidegger na tentativa em comum se de opor à tradição metafísica (moderna). O principal opositor declarado de Kierkegaard é Hegel (ABOULAFIA, 2001, p.61) e o principal 
opositor não-declarado de Heidegger também é Hegel (ROBINSON, 2005, p.360), muito embora ele tente escamotear tal oposição ao se opor mais veementemente a Descartes (por exemplo, ao rejeitar a distinção cartesiana clássica entre sujeito e objeto). Por mais que os intentos de Kierkegaard e de Heidegger ao rivalizarem com Hegel fossem diversos (Kierkegaard queria extirpar a sistemática materialista ao passo que Heidegger tinha pretensões mais amplas de se tomar o lugar dele como educador da contemporaneidade, sob a égide de um entendimento platônico da realidade), a crítica à metafísica operada pelos dois pensadores debatidos é mais um elemento de sua aproximação teórica.

Nenhum dos dois pensadores (nem Kierkegaard nem Heidegger) almeja criticar a metafísica apenas como uma atividade diletante em seus estudos, e escolhem tópicos bastante similares para tal. A diferença mais marcante de Heidegger, nessa seara, diz respeito à assunção metodológica da fenomenologia, algo que não se verifica em Kierkegaard.

Diferentemente de Kierkegaard, que constrói uma escada ${ }^{11}$ para ascender seu pensamento rumo ao conhecimento ético-religioso (FORSBERG, 2013, p.97), Heidegger não tem uma perspectiva ética declarada na primeira fase do seu pensamento, muito embora uma parte muito pequena das suas ideias mais originais seja dita de modo tão direto quanto outros pensadores fazem (a exemplo do próprio Kierkegaard). Nesse ponto, parece que Heidegger se interessa mais em tornar o acesso a tais "doutrinas" mais elevadas algo difícil, pois tais ensinamentos se encontram encobertos sob a escrita do seu texto principal, sendo necessário garimpar boa parte desse entendimento, tal como ocorre com grande parte do conteúdo que ele coleta em Kierkegaard, o qual não se encontra necessariamente citado em notas de rodapé, tal como indicado no início dessa seção. Heidegger não se vale da metáfora da escada para pavimentar seu existencialismo (STOREY, 2015, p.37), ao invés disso ele investe na perspectiva fenomenológica para assentar o

\footnotetext{
11 Nesse sentido, James Conant (1995, p.201) indica que a abordagem kierkegaardiana através de pseudônimos (no caso em tela, Climacus) expõe a sua tentativa retórica em não ter um posicionamento (próprio) que expresse uma verdade derradeira sobre os assuntos que ele mesmo levanta e debate (principalmente no Post-Scriptum), as palavras do pseudônimo não necessariamente correspondem à posição ou ao entendimento de Kierkegaard sobre os temas debatidos em suas obras. Assim, Climacus (e não Kierkegaard em nome próprio, ressalte-se) investiga o cristianismo sob a lente de uma contradição performativa (LEAR, 2011, p.40). Essa é uma forma de o leitor (intérprete das "migalhas filosóficas" kierkegaardianas) poder reconhecer suas próprias confusões. A contradição performativa põe frente a frente 0 desinteresse da objetividade pelo cristianismo pela busca ardentemente apaixonada $\mathrm{e}$ subjetiva pelo modelo de vida cristão. Essa oposição contraditória por si mesma, ela é operada segundo o padrão da escalada (do aprofundamento na interioridade subjetiva) e vislumbra o compasso do desenvolvimento da performance pseudonômica e retórica de Kierkegaard.
} 
conteúdo de sua crítica à metafísica. Assim, percebe-se que o tratamento dado à questão por Kierkegaard é mais direto e mais incisivo naquilo que ele pretende criticar (a sistematicidade e o materialismo hegeliano), ao passo que Heidegger insiste em remissões terminológicas inovadoras para estruturar originariamente o seu pensamento na nova ramificação do existencialismo, o existencialismo-fenomenológico.

Não se está a dizer que a crítica à metafísica tal como operada por Heidegger seja algo escondido ou indireto, ao contrário disso, certamente sua crítica é direta ao centrar esforços na dualidade sujeito-objeto e na noção de verdade como correspondência, tais elementos são delineados de forma acrisolada em Ser e Tempo. O que acaba por se esconder ou por ficar pouco claro no texto em destaque é a contraposição heideggeriana a alguns entendimentos hegelianos, contraposição crítica essa que Heidegger parece confiar indiretamente em Kierkegaard para se valer de tais argumentações sem precisar coloca-las diretamente sobre a mesa. Toda a sistemática e toda a conceituação hegeliana já criticada por Kierkegaard também é rejeitada (não expressamente, ressalte-se) por Heidegger, afinal, ele almeja a construção de um entendimento despido de tais máculas. A sua tentativa de retorno ao que foi esquecido na questão sobre o ser (Seinfrage) tem por intento rejeitar toda a metafísica construída com o escopo de encobrir historicamente essa questão (DUNCAN, 2001, p.39). Dessa maneira, rejeitar a metafísica consiste em rejeitar doutrinas hegelianas, embora Heidegger não faça isso de modo direto e claro, tal premissa se evidencia ao se notar que seu entendimento é de raiz fortemente kierkegaardiana, o que o capacita como um crítico de Hegel, ainda que por uma análise indiretamente enviesada.

Derradeiramente, para dar um fechamento adequado a presente seção é necessário traçar um quadro comparativo que agregue os entendimentos compartilhados entre eles. Assim chega-se a uma continuidade interpretativa que é repartida entre os autores estudados até então. O ponto central que agrega todos eles, de um modo mais direto, é a questão da crítica a metafísica. O pensamento kierkegaardiano, de modo geral, serve como base de alimentação anti-metafísica para a primeira fase do pensamento de Heidegger.

O ponto perene na análise dos autores estudados é a questão da apresentação do mundo como um elemento externo que não pode ser simplesmente conhecido pelo homem, tal qual uma mera acessibilidade cognitiva baseada na dualidade moderna estruturada em sujeito conhecedor e objeto conhecido. Heidegger, portanto, critica o estabelecimento dualista entre o sujeito e o objeto. Por causa do elemento comum de crítica, ele prevê que uma modalidade diversa de conhecimento deve ser buscada pelo homem (ou Dasein, na terminologia anti-metafísica heideggeriana). 
Nesse empreendimento, a verdade, a "subjetividade" e o conhecimento alcançados são sempre temas de grande relevância para os autores em estudo. Embora suas asserções conceituais variem, em algum aspecto por causa do lapso temporal entre eles, e em outro aspecto por uma questão de originalidade própria de cada autor, o entendimento final é basicamente o mesmo. São expressões equivalentes dizer que "a verdade é a subjetividade" ou que "o Dasein é e está na verdade". Essas expressões pertencem a uma mesma linha de pensamento, frequentemente denominada na tese em desenvolvimento como culturalismo.

O debate contemporâneo empreendido pelos autores abordados os alinha de modo semelhante. Eles não estão interessados, necessariamente, no desenvolvimento "cientificista" da filosofia, contrariamente, ancoram-se numa compreensão mais prática e efetiva da vida do homem como cerne de suas elucubrações.

Por fim, há de se destacar que a secularização operada por Heidegger segue os ditames transteísticos, tal qual eles já foram adequadamente definidos e escrutinados previamente. Nesse sentido, há de se ponderar que o entendimento diferenciado dos mencionados autores não viola, de modo algum, o âmago interpretativo levantado por Kierkegaard e posteriormente revisitado por Heidegger. Os elementos principais kierkegaardianos podem ser repetidos com a mesma prevalência cultural, segundo os moldes transteísticos, sem que isso vilipendie ou aniquilo a relevância por ele dada a tais temas.

Essa forma de apresentação transteística se amolda melhor ao contexto contemporâneo encarado por Heidegger, serve como um meio de transmissão da inserção cultural do homem segundo o seu próprio tempo histórico. O transteísmo, tal como colocado, é uma forma ainda mais ampla de designar as possibilidades do homem, haja vista que ele de modo algum tem o intento de rejeitar as asserções ético-religiosas de Kierkegaard, por exemplo. Contrariamente, a perspectiva transteística repartida por Heidegger possibilita o exercício da crença cristã nos exatos moldes praticados (ou ao menos propostos por Kierkegaard, afinal o trabalho não se debruça especificamente sobre sua biografia) sem excluir formas de expressão religiosas (ou não) do enquadramento pela busca da "verdade" ou daquilo que serve como elemento básico de proposições elementares. Em síntese, pode-se enunciar que a perspectiva cristã, tal como pensada por Kierkegaard, ainda remanesce como uma forma ético-religiosa de aprofundamento ético-religioso direcionado para a verdade de cada um segundo seus próprios entendimentos culturais de convivência. 


\section{Considerações finais}

Em conclusão aos elementos expostos no desenvolvimento do trabalho, pode-se indicar, derradeiramente, que a influência kierkegaardiana no pensamento de Heidegger é maior e mais prevalente do que ele jamais poderia admitir em apenas duas singelas notas de rodapé em Ser e Tempo. Aliás, é de grande valia perceber que nas próprias notas de rodapé indicadas por Heidegger ele não as finaliza enaltecendo o pensamento ou a influência de Kierkegaard, pelo contrário, ele sempre se preocupa em indicar quais os pormenores que invalidam plenamente o pensamento kierkegaardiano para que a sua posição seja prevalente. Esses indicativos não são ominosos por si mesmos, todavia, perdem força argumentativa quando se observa que atribuir a pecha de "psicólogo" ou de "teólogo" a Kierkegaard não o desmerece, tampouco o status ontológico escrutinado por Heidegger seria de alguma forma alcançável na época por Kierkegaard, basicamente em virtude de seu aparato terminológico e conceitual ser hegeliano (e não heideggeriano, por uma impossibilidade temporal).

Dessa forma, encaminha-se no terceiro terço do artigo para a análise conjunta do tema da verdade e da subjetividade, e como esses dois elementos estão entrelaçados na visão dos dois pensadores em discussão. Observa-se que a influência kierkegaardiana na primeira fase do pensamento de Heidegger, a esse respeito, é significativa ao ponto de se supor que houve apenas uma remodelagem por parte do filósofo alemão, e não propriamente indicativos originários de um pensamento novo. Heidegger por mais que tente se afastar da influência kierkegaardiana ao assumir uma postura secular, não consegue se desvencilhar totalmente do adágio de Kierkegaard que "a subjetividade é a verdade", sempre tendo como norte a diferença terminológica de ambos os autores, sob pena de se recair em um anacronismo patente.

Assim, há de se concluir que não apenas a influência de Kierkegaard sobre Heidegger é salutar, especialmente na sua primeira fase, mas que além de não admitir certos pontos de influência, esses elementos "pretensamente" esquecidos de terem sido mencionados revelam que Heidegger almejava apenas remodelar o pensamento kierkegaardiano, sem, propriamente, fazer uma mudança profunda e radical em suas estruturas mais elementares e básicas. 


\section{Referências}

ABOULAFIA, M. The Cosmopolitan Self: George Herbert Mead and Continental Philosophy. Chicago: Chicago UP, 2001.

BOWIE, A. Aesthetics and Subjectivity: From Kant to Nietzsche. Manchester, UK: Manchester UP, 2003.

CARLISLE, C. Kierkegaard's Philosophy of Becoming: Movements and Positions. Albany: SUNY Press, 2005.

CONANT, J. F. "Putting Two and Two Together: Kierkegaard, Wittgenstein and the Point of View for Their Work as Authors". In: TESSIN, Timothy; VON DER RUHR, M. Philosophy and the Grammar of Religious Belief. New York, St. Martin's Press, 1995, p.249-304.

CAPUTO, J. D. Radical Hermeneutics: Repetition, Deconstruction, and the Hermeneutic Project. Bloomington: Indiana UP, 1987.

CROCKETT, C. Secular Theology: American Radical Theological Thought. London: Routledge, 2001.

DORNENREICH. "Wer hat Angst vor Einsamkeit?" [Jochen Stock]. In: . Her von welken Nächten. Zeltingen-Rachtig: Prophecy Productions, 2001. 1 CD (ca. 58 min 53 s). Faixa 3 (ca. 06 min 19s). Remasterizado em digital.

DUNCAN, D. The Pre-text of Ethics: on Derrida and Levinas. New York: Peter Lang, 2001.

ELROD, J. W. Being and Existence in Kierkegaard's Pseudonymous Works. Princeton: Princeton UP, 1975.

FIGAL, G. Phänomenologie der Freiheit. 3. ed. Weinheim: Beltz Athenäum, 2000.

FORSBERG, N. Language Lost and Found on Iris Murdoch and the Limits of Philosophical Discourse. New York: Bloomsbury, 2013.

HADOT, P. Le Voile d'Isis Essai sur l'historie de l'idée de Nature. Paris: Gallimard, 2004.

HEGEL, G. W. F. Phenomenology of Spirit. Trad. Arnold V. Miller. Oxford: Oxford UP, 1977.

HEIDEGGER, M. A Origem da Obra de Arte. Trad. Maria da Conceição Costa. Lisboa: Edições 70, 2007. 
. Ser e Tempo. Trad. Márcia Sá Cavalcante Schüback. 3. ed. Rio de Janeiro: Vozes, 2008.

KIERKEGAARD, S. O Conceito de Angústia: uma simples reflexão psicológicodemonstrativa direcionada ao problema dogmático do pecado bereditário de Vigilius Haufniensis. Trad. Álvaro Valls. Petrópolis: Vozes, 2011.

. O Conceito de Ironia: constantemente referido a Sócrates. Trad. Álvaro Luiz Montenegro Valls. Petrópolis: Vozes, 1991.

. Estética y Ética: en la formación de la personalidad. Trad. Armand Marot. Buenos Aires: Nova, 1955. . Post Scriptum no científico y definitivo a "Migajas filosóficas". Trad. Javier Teira e Nekane Legarreta. Salamanca: Ediciones Sígueme, 2010.

KING, M. A guide to Heidegger's Being and Time. Albany: SUNY Press, 2001.

LEAR, J. A Case for Irony. Cambridge: Harvard UP, 2011.

MALPAS, J. Heidegger's Topology: Being, Place, World. Cambridge: MIT Press, 2006.

MJÅLAND, M. Autopsia: Self, Death, and God after Kierkegaard and Derrida. Berlin: Walter de Gruyter, 2008.

MCCARTHY, V. A. The Phenomenology of Moods in Kierkegaard. The Hague: Martinius Nijhoff, 1978.

MOUNIER, E. Introduction aux Existentialismes. Paris: Gallimard, 1962.

PATTISON, G. Kierkegaard and the Theology of the Nineteenth Century: The Paradox and the 'Point of Contact'. Cambridge: Cambridge UP, 2012.

ROBINSON, J. The Mass and Modernity: Walking to Heaven Backward. San Francisco: Ignatius Press, 2005.

SPINOZA, B. Ethics: Demonstrated in Geometrical Order. Trad. W. H. White, A. K. Stirling. Hertfordshire: Woodsworth, 2001.

STOREY, D. Naturalizing Heidegger. His Confrontation with Nietzsche, his Contributions to Environmental Philosophy. Albany: SUNY Press, 2015.

TANNER, J. S. Anxiety in Eden: A Kierkegaardian reading of Paradise Lost. New York: Oxford UP, 1992.

TILLICH, P. The Courage to Be. New Haven: Yale UP, 2014. 
TOEWS, J. E. Hegelianism: The Path Toward Dialectical Humanism, 1805-1841. Cambridge: Cambridge UP, 1980.

WAHL, J. Études Kierkegaardiennes. 4. ed. Paris: Librairie Philosophique J. Vrin, 1974.

WARE, K. Act out of Stillness: The Influence of Fourteenth-Century Hesychasm on Byzantine and Slavic Civilization. Toronto: The Hellenic Canadian Association of Constantinople and the Thessalonikean Society of Metro Toronto, 1995.

WRATHALL, M. Heidegger and Unconcealment: Truth, Language, and History. Cambridge, Cambridge UP, 2011.

E-mail: lauroericksen@yahoo.com.br

Recebido: 08/12/2016

Aprovado: 04/05/2017 